\title{
The Reality of Secondary Education in Jordan from the Perspective of Secondary School Principals
}

\author{
Haroon Mohammad Al Tawarah ${ }^{1}$ \\ ${ }^{1}$ Al Shoubak College, Al-Balqa' Applied University, Al Shoubak, Jordan \\ Correspondence: Haroon Mohammad Al Tawarah, Al Shoubak College, Al-Balqa' Applied University, Al \\ Shoubak, Jordan. Tel: 77-777-4520. E-mail: htawarah55@gmail.com
}

Received: August 16, 2018

doi:10.5539/ies.v12n2p19
Accepted: September 30, $2018 \quad$ Online Published: January 30, 2019

URL: https://doi.org/10.5539/ies.v12n2p19

\begin{abstract}
The study aims at assessing the reality of secondary education in Jordan from the high school principals' perspective, in addition to figuring out the impact of the gender differences on the results. To answer the study questions; the researcher selected the study sample using the stratified random method. The sample consisted of 73 headmaster and headmistress of secondary school from the southern governorates of Jordan (Ma'an, Al Shoubak, Petra, Southern Badia, and Aqaba) for the academic year 2017/2018. The researcher developed a questionnaire consisted of (35) paragraphs, divided into five fields: (building and equipment, students, teaching staff, curricula and educational supervision) and for the combined fields as well. The results of the study revealed the following: (1) Principals' assessment of the two fields of building and equipment, and students, and for the fields combined was high (2) Principals' assessment of teaching staff, curricula, and educational supervision was medium (3) Principals' assessment of the questionnaire was not affected by the gender.
\end{abstract}

Keywords: education in Jordan, reality of education, secondary schools, secondary education

\section{Introduction}

The educational institutions are considered as the real place for human development, investing and transforming their energies to be productive. The human being is the most important factor in the field of knowledge economy. In our modern era, education has become a necessity for human life. Human being therefore can master skills and reach the goals that lead to excellence through the production of renewed knowledge (Shakshak, 2005).

Education is more than a national wealth if used wisely, which can be achieved by introducing modern sciences and high technology into the curricula. Whereas, education has become an important pillar in the national projects, for its link with the needs of the individual and society and its importance in raising productivity. This was accompanied by advanced training and educational programs (Ashour, 2010).

The educational process in Jordan has shown a remarkable growth in all stages, represented by the Ministry of Education, which was achieved through the preparation of educational programs and the capacity building of the teaching staff on the cognitive and skill levels, in order to obtain the targeted educational outputs. Thus, education, especially secondary education, has become an important pillar in development.

The education system in Jordan has undergone continuous improvement since the middle of the 20th century, to become one of the best educational systems in the developing countries. This system adopted the first phase of the 10-year Educational Reform for Knowledge Economy Program, while the second phase of the program aimed at enhancing and institutionalizing the reforms that have been applied in the first phase. Special attention was given to teachers' competences to strengthen their capacity for planning, evaluation, professional development, curricula development, teaching methods, and the educational environments, all to be in harmony with knowledge -based economy (World Bank, 2009).

The secondary educational system in Jordan consists of two academic years, for students who completed the basic stage, and has two main streams, as the following:

1) The academic or vocational secondary education. The academic stream qualifies students to enroll in universities, while the vocational or technical stream qualifies them to enroll in intermediate community colleges or join the labor market. 
2) The applied secondary education, which provides intensive vocational training and apprenticeship, it therefore qualifies students to obtain the professional practice certificate.

Jordan still needs to focus on improving secondary educational quality. Thus, through the international assessments such as the Trends in the International Mathematics and Science Study (TIMSS) and International Program for Student Assessment; Jordan performance was evaluated as good in comparison to other Arab countries but has lagged many other countries with similar levels of the educational expenditure (Journal of Scientific Research, 2009).

Many studies have been conducted in the neighboring countries including the study of Al-Fatlawi (2012), which aimed at determining the reality of secondary education and its problems in the province of Karbala and the outlook of secondary education. The study discussed the fields of buildings, students, curricula, supervision and school administration. As per the study results, the students, educational staff, supervisors and the parents expressed their dissatisfaction with the secondary education. The researcher has therefore reached to the outlook that he sets for the secondary education to change its reality through: 1) reconsidering the objectives of the secondary education, 2) selecting the qualified leaders to lead the educational process, 3) paying attention to school buildings, curricula, 4) preparing specialized educational personnel, in addition to the good selection of the educational supervisors.

Moreover, Al-Qahtani (2007) conducted a study which aimed at formulating a vision for the future development of the secondary educational system for males in kingdom of Saudi Arabia in the light of the international experiences and thus formulating a future vision for the structure of this system and the proposed mechanisms for the implementation. After analyzing the opinions of specialized experts and those interested in the secondary education, the study reached some results including: 1) keeping the scientific stream in secondary education, 2) adopting the comprehensive school model, and 3) full-time learning by the secondary students.

Al-Jawish (2006) conducted a study aimed at showing how to benefit from the contemporary global trends in secondary education and developing the productive school in Egypt. The study found 1) the importance of linking the theoretical and practical education, 2) eliminating the gap between them, 3) reducing the centralization by giving more powers for school principals, and 4) enriching the content of the curricula with modern technological applications of natural sciences.

Wright (2004) conducted a study which aimed at revealing the status of schools at postwar period in Iraq. The study found that thousands of school facilities lack basic infrastructure necessary to provide the decent education for Iraqis' student. The results also showed that one third of the elementary schools in Iraq do not have water supply sources, and nearly half of them lack health facilities, also the number of school buildings is insufficient to cope with the growing demand for education.

\section{Study Problem and Objectives}

In line with the educational development programs that called for improving the educational process elements; the interest in various stages of the educational process has increased, where the secondary school became a center for rehabilitation and training, in addition to its role in providing the community with the scientific knowledge and directing it towards activities that generate income and develop the economy. Hence, the education under the new vision started to take into considered the new comparison between costs and benefits, which should be monitored from time to time. The researcher opted to study the reality of secondary education in Jordan from the perception of the school administrations which have the most important impact in the school. This can be limited to the following fields: buildings and equipment, curricula, faculty, students, and the educational supervision.

\subsection{The Study Objectives}

This study aims at:

- Investigating and exploring the reality of the secondary education in Jordan.

- Identifying the challenges facing the secondary education in Jordan.

- Providing a new outlook for the secondary education Jordan.

\subsection{Questions of the Study}

Sample answers on the study tool, i. e., the questioner, were analyzed to answer the following two questions of the study:

Question 1: What is the reality of the secondary education in Jordan from the perception of the secondary school principals for each of the five fields (building and equipment, students, staff teaching, curricula, educational 
supervision) and the fields combined?

Question 2: Are there statistically significant differences at the significance level of $(a=0.05)$ in the principals' assessment attributed to the gender factor?

\subsection{Study Importance}

Exploring the effective role of the secondary schools, from the school principals' perspective, and the extent to which they achieve the objectives pursued by the educational institutions, in addition to developing and improving the secondary schools and identifying the impact of gender.

The questionnaire was distributed on the study sample to identify the principals' opinions.

\subsection{The Study Related Definitions}

1) The Secondary School: An educational institution which its educational system consists of two academic years, for the students who completed the elementary stage. It includes academic, professional and applied streams.

2) The School Principals: An educational group that leads the educational process in the school and contributes towards the educational policies development and oversees the implementation of such policies.

\subsection{The Study Limits}

The study was geographically limited to the southern governorates schools (Ma'an, Al Shoubak, Petra, Southern Badia, and Aqaba) for the academic year 2017/2018.

\section{Methodology}

\subsection{Method and Procedures}

The descriptive survey method was applied using the questionnaire as a data collection tool as being suitable for the study.

\subsection{Study Community}

The study community was formed of 73 headmaster and headmistress from the secondary schools in the southern governorates of Jordan (Ma'an, Al Shoubak, Petra, Southern Badia, and Aqaba) for the year 2017/2018.

Table 1. Study sample features

\begin{tabular}{cccc}
\hline \multirow{2}{*}{ Directorate } & \multicolumn{2}{c}{ Gender } & \multirow{2}{*}{ Total } \\
\cline { 2 - 3 } & Male & Female & \\
\hline Ma'an & 4 & 3 & 7 \\
Petra & 5 & 4 & 9 \\
Aqaba & 13 & 12 & 25 \\
Al Shoubak & 3 & 3 & 6 \\
Badia & 13 & 13 & 26 \\
Total & 38 & 35 & 73 \\
\hline
\end{tabular}

The study sample included all members of the study community which consists of 73 headmaster and headmistresses.

\subsection{The Study Tool and its Validity}

The researcher conducted the following steps to come up with the results:

1. He prepared the questionnaire about the secondary school principals' perception regarding the reality of the secondary education in Jordan, according to their assessment of the five fields; (the building and equipment, students, teaching staff, curricula and educational supervision) based on: 1) the educational literature, including the General Framework of Curricula issued in 2003 and 2) his previous experience in the supervision and curricula.

2. He also reviewed several previous studies to enrich his study.

3. He then presented the questionnaire to five specialists in the educational sciences from the Jordanian universities as arbitrators. All the 35 paragraphs were approved by the arbitrators after carrying out the necessary linguistic and technical modifications. 
4. The response to each paragraph of the questionnaire was measured according to Likert Scale, which consists of five degrees, the lowest is "very small" and the highest is "very big". The response of (very big) was given five degrees, while the response of (very small) was given one degree. The figure 5 indicates the maximum degree and figure 1 indicates the minimum degree for the paragraph. The resulted averages were used as references to compare the degrees of assessment in the responses of the sample community as follows: High: equal 3.7 or greater, Medium: less than 3.7 and equal or greater than 3, Weak: less than 3.

5. Reliability coefficient was also calculated using the Cronbach's alpha equation for the whole questionnaire and each field of it as shown in Table 2.

Table 2. Fields of the questionnaire \& paragraphs in their final form

\begin{tabular}{ccc}
\hline Area & No. of Paragraphs & Reliability Coefficient \\
\hline Building \& Equipment & 7 & 0.93 \\
Students & 7 & 0.89 \\
Teaching Staff & 7 & 0.92 \\
Curricula & 7 & 0.90 \\
Educational Supervision & 7 & 0.91 \\
Total Reliability & & 0.91 \\
\hline
\end{tabular}

\subsection{Procedures of the Study}

Execution the study entailed the following main procedures:

1. Identifying the study sample and verifying the tool validity \& reliability.

2. Distributing 73 questionnaires among the study sample and results were collected and documented.

3. Processing the results using the arithmetic mean and the standard deviation for the first question, while the (one-Way Anova) analysis was used for the second question.

\section{Results and Discussion}

Results of the study will be shown for question 1 then for question 2 .

Question 1: What is the reality of the secondary education in Jordan from the perspective of secondary school principals for each of the five fields (building and equipment, students, teaching staff, curricula, educational supervision) and for the fields combined?

Table 3. Ranking the questionnaire fields according to the answers

\begin{tabular}{ccccc}
\hline $\begin{array}{c}\text { Paragraph serial in the } \\
\text { questionnaire }\end{array}$ & Paragraph Text & $\begin{array}{c}\text { Arithmetic } \\
\text { Mean }\end{array}$ & $\begin{array}{c}\text { Standard } \\
\text { Deviation }\end{array}$ & $\begin{array}{c}\text { Paragraph number according to } \\
\text { responses }\end{array}$ \\
\hline 1 & Students & 3.92 & 0.19 \\
2 & Building \& Equipment & 3.89 & 0.22 & 3 \\
3 & Teaching staff & 3.66 & 0.33 \\
4 & Educational & 3.65 & 0.32 \\
5 & Supervision & 3.46 & 0.42 \\
\hline
\end{tabular}

The results of the study showed that the area of the students ranked as first, followed by the area of building and equipment, where the least was the area of the curricula. About the area of students that most of its items got the highest degree in the assessment, the items of the highest assessment are: 1) the democratic behavior, 2) taking into consideration the students' preferences in school programs, 3) their positive attitude towards the educational institution and the regulations and instructions applied, and 4) the respect for teachers. The area of building and equipment that focuses on school building came second as the most important factor for a successful classroom environment, the items of this paragraph include: 1) the school safe location and good maintenance, 2) the space of classrooms, 3) the availability of laboratories and resources rooms, and 4) the maintenance of school facilities.

The results were agreed with the study of (Al-Fatlawi, 2012) in the aspects of teachers and supervision, and 
differed in the aspects of the buildings. It also disagreed with (Wright, 2004) study which showed the poor school buildings and (Al-Jawish, 2006) study which showed the focus on the theoretical aspects. This progress may be attributed to the modern educational policy which adopted the concept of the knowledge economy in terms of theory and practice. It also focused on taking into consideration individual differences among students and organizing educational experiences.

This modern policy considers the learner as the core of the educational process, where the educator must respect his personality and give him the opportunity to express his interests and wishes. This aims at applying democracy at school and society, in addition to providing a school environment that respects the learners and their abilities, and stimulates their motivation for research and exploration, with the advent of school buildings equipped with requirements, preparing them to suit the student's conditions, in order to activate and develop the education and achieve the vision which considers the school as the corner stone in the educational process.

Moreover, the area of the teaching staff got a medium degree of the assessment, where its items included: 1) taking the initiative to lead the educational process, 2) providing the motivation, 3) the use of technology methods in teaching, 4) sharing responsibility with the school administration, and 5) conducting courses and the pursuit of effective teaching and team work.

The area of teaching staff was followed by the area of the supervision which included: 1) the follow-up field visits, 2) keeping pace with modern educational developments, 3) using the educational research in solving the problems and developing the rules of communication and participation in the development and evaluation of administrative plans and educational development programs, as well as the enrichment of the educational process.

The last rank was given to the curricula which included: 1) the provision of manuals to teachers, 2) how to meet the students' needs, 3) considering the individual differences, 4) keeping pace with global changes and stimulating good thinking. Even though it is in the middle, but it has taken its way and began to make an impact, and may grow with the coming days, but it needs an institutional support capable of making the required change to renew the educational reality. The researcher beliefs that the curricula need continues revision in order to change, modify and purify the curricula from any unacceptable ideas to suit the ideological principles that reflect the national policy.

As for the overall assessment of the questionnaire, it came at the lowest point of the high level, with an arithmetic average of 3.71. According to the researcher, this average is high when compared with Arab world. The graduates from the secondary schools in Jordan from both the academic and the vocational streams have showed excellence in teaching sector and in work places in different Arab countries. On the other hand, educational policies in the Arab world are not advances or matured enough to be compared with those adopted by the West. The researcher believes that the reason is the weak use of technology; the lack of educational responsibility; and the burdens placed on the educational institutions, which shift attention to certain aspects over others. Furthermore, most people in the Arab world believe that our educational issues reflect the dominance of the powerful countries on our culture and education.

Question 2: Are there statistically significant differences at the significance level of $(a=0.05)$ in the principals' assessment that attributed to the gender factor?

Table 4. Results of One-Way Anova test for the gender impact

\begin{tabular}{cccccc}
\hline & Sum of Squares & Degrees of Freedom & Average of Groups & "T" Value & Statistical Significance \\
\hline Between Groups & 11.647 & 41 & 0.284 & 1.641 & 0.078 \\
Within Groups & 5.367 & 31 & 0.173 & & \\
Total & 17.014 & 72 & & & \\
\hline
\end{tabular}

The table above indicates that there are no statistically significant differences between the two genders, which means the absence of the gender impact. According to the researcher, this result proves that both headmasters and headmistresses have similar judgment on the educational reality as they have the same work circumstances and the same suffer as well.

Based on the results of the study that highlighted some issues regarding the secondary education in Jordan, the following recommendations are suggested:

- Adopting the school administration recommendations as part of the assessment and review process adopted by the institution responsible for the educational policies.

- Following-up the reality of supervision, curricula, and the teacher to find solutions that would avoid or 
mitigate the weakness points appear.

- Giving more attention to teachers through building their capacity and activating their educational research efforts to reach the target of developing the secondary school.

\section{References}

Al-Fatlawi, A. (2012). An Outlook for the Reality of Secondary Education in the Province of Karbala. Journal of Humanities (special volume of the conference), 1(11).

Al-Jawish, H. A. (2006). Contemporary Global Trends in Secondary Education and How to Use them for the Development of the Productive School (PhD thesis, Egypt).

Al-Qahtani, M. S. (2007). Outlook for Developing the Structure of Secondary Education System for Males in Saudi Arabia (Unpublished PhD thesis). Umm Al Qura University, Faculty of Education. Kingdom of Saudi Arabia.

Ashour, M. A. (2010). Secondary Education in Jordan is an Entrance to Higher Education and Professional Labor Market. The Arab Organization for Administrative Development, Manama.

Journal of Scientific Research. (2009). Jordanian Association for Scientific Research (Issue No.1).

Shakshak, A. A. (2005). Education is the Industry of Human Being. Dar Al-Hafez for Book, Syria.

World Bank. (2009). Reform of Education for Knowledge Economy, project II. Project Evaluation Document.

Wright, R. (2004). Schools in Iraq Suffer from Neglect and the Effects of War. Arab Network for Human Rights Information. Jordan Network for Development.

\section{Copyrights}

Copyright for this article is retained by the author(s), with first publication rights granted to the journal.

This is an open-access article distributed under the terms and conditions of the Creative Commons Attribution license (http://creativecommons.org/licenses/by/4.0/). 